\title{
Reconnecting in the Face of Exclusion: Individuals with High Social Anxiety May Feel the Push of Social Pain, but not the Pull of Social Rewards
}

\author{
Taylor Hudd ${ }^{1}$. . David A. Moscovitch ${ }^{1}$
}

Accepted: 11 August 2021 / Published online: 17 August 2021

(c) The Author(s), under exclusive licence to Springer Science+Business Media, LLC, part of Springer Nature 2021

\begin{abstract}
Background Previous research has shown that high levels of trait social anxiety (SA) disrupt the social repair processes following a painful social exclusion, but the cognitive mechanisms involved in these processes and how trait SA may disrupt them remain unknown.

Methods We conducted a preregistered study on Prolific participants $(N=452)$ who were assigned to experience either social exclusion or inclusion and were then exposed to follow-up opportunities for social reconnection.

Results Moderated mediation analyses revealed that irrespective of levels of SA, participants responded to social pain with heightened approach motivation and greater downstream positive affect. Exploratory analyses revealed that heightened desire to affiliate was driven by increased curiosity and attention to social rewards. Moreover, higher SA was associated with lower overall desire to affiliate and this relationship between SA and affiliation was mediated by diminished reward responsiveness. Conclusions Findings highlight the roles of goal pursuit and social reward responsiveness in social repair and how high levels of trait SA may disrupt these processes.
\end{abstract}

Keywords Social pain $\cdot$ Social anxiety $\cdot$ Social rewards $\cdot$ Curiosity $\cdot$ Prediction error

When others reject or exclude us, the need to belong becomes thwarted (Zadro et al., 2004), eliciting feelings of social pain (Eisenberger, 2015; Eisenberger et al., 2003). Social pain is an emotional distress signal that activates neurological response patterns resembling physical pain, highlighting the importance of forming social bonds for our ancestors' survival and reproduction (Eisenberger, 2012; MacDonald \& Leary, 2005).

Of course, signaling that damage to a social network has taken place is only helpful if it motivates a functional or adaptive response. Adaptive behaviours within this context may include those that re-establish or promote new social bonds or protect against further social ostracism. In this vein, researchers have discovered that when there is reasonable opportunity for social connection following exclusion,

Taylor Hudd

thudd@uwaterloo.ca

1 Department of Psychology and Centre for Mental Health Research and Treatment, University of Waterloo, Waterloo, ON N2L-3G1, Canada people often increase their efforts to bond with others by becoming more affiliative (Narayanan et al., 2013). Excluded participants also engage in more generous acts toward others and make attempts to increase their proximity to others (Chester et al., 2016; DeWall et al., 2009; Maner et al., 2007; Mead et al., 2011; Romero-Canyas et al., 2010; Sommer \& Bernieri, 2015). Moreover, excluded participants increase their affiliative efforts through reciprocal interpersonal behaviours, such as mirroring, even when exclusion has made them less trusting and more critical of others (DerflerRozin et al., 2010; Sommer \& Bernieri, 2015).

\section{Social Anxiety and Dampened Desire to Reconnect}

Notably, certain trait-like tendencies appear to undermine this social repair process. In particular, studies have shown that those with high trait levels of social anxiety (SA) do not heighten their affiliative efforts in response to socially painful events (Hudd \& Moscovitch, 2020; Maner et al., 2007), an effect that remains robust even after controlling 
for depressive symptoms (Mallott et al., 2009). These effects could inform pathways through which SA symptoms become elevated and maintained. To this end, Fung and Alden (2016) showed that the intensity of social pain following social exclusion in an initial social encounter mediated levels of anxiety participants experienced in anticipation of a subsequent social interaction, suggesting the negative impact of social pain may be carried forward into future social encounters. Social repair processes may function to alleviate the sustained negative effects of social pain and, in their absence, individuals might carry with them the full weight of a socially painful event.

There are at least two ways that high levels of trait SA may impede individuals from approaching and affiliating with others in the face of painful exclusion. SA has long been characterized as a fear-based problem (Clark \& Wells, 1995), in which symptoms are borne out of beliefs that the self is fundamentally deficient and that such self-flaws be concealed from others to prevent negative evaluation (see Moscovitch, 2009). Entering social interactions with such negative appraisals of the self in relation to others may lower their threshold for perceiving threat cues that signify the possibility of social rejection (Bantin et al., 2016; Harb et al., 2002). Thus, oversensitivity to threat (e.g., excessive attention and responsivity to threat signals) may be one important factor that motivates people with high SA to prevent further damage and "cut their losses" by socially withdrawing in response to social exclusion, rather than heightening their affiliative efforts (see also Bielak \& Moscovitch, 2013; Moscovitch et al., 2012, 2015; Steinman et al., 2014).

A second factor that may explain how high SA may impede affiliation following exclusion emerges from a growing body of research suggesting that SA symptomology is not only driven by an overactive threat-avoidance motivational system, but also an underactive rewardseeking approach system, particularly within interpersonal contexts (see Blay et al., 2021; Weisman et al., 2011). From this perspective, high SA may inhibit desire to affiliate, perhaps by dampening goal pursuit and social reward responsivity in the face of painful exclusion. Indeed, evidence is accumulating in support of the view that those with high SA demonstrate a broad pattern of diminished reward responsiveness (Richey et al., 2019). Individuals with high SA also display reduced neural connectivity in reward centres during resting states (Manning et al., 2015), suggesting that even if rewards are recognized, higher SA individuals may not have the capacity to respond emotionally to the same degree as their low SA counterparts. Studies have also found that participants with high trait SA exhibit reduced neural activation in anticipation of social rewards compared to the levels of activation exhibited in response to social punishments or non-social (monetary) rewards (Cremers et al., 2015; Richey et al., 2014).

A key component of the social repair process following exclusion appears to be the activation of motivated social goal pursuit, which, if successful, can promote heightened downstream positive affect-especially when a feasible avenue for affiliative reconnection is made available (Hudd \& Moscovitch, 2020; Maner et al., 2007). To this end, research has shown that the activation of goal-oriented social approach motivations is associated with greater recognition of social reward potential (Anderson \& Berdahl, 2002; Kunstman \& Maner, 2011; Min \& Kim, 2013) and that excluded participants become more attentive to social reward signals at early stages of cognitive processing (i.e., noticing smiling faces) (DeWall et al., 2009). The pull of rewards could explain why non-anxious individuals who have been excluded tend to experience a heightened desire for social reconnection, even when they are negatively affected by the initial threat of exclusion. In contrast, people with social anxiety disorder (SAD) displayed inhibit reward processing while under scrutiny (Becker et al., 2017), suggesting the looming threat of social evaluation may hinder their ability to feel rewarded when receiving positive feedback. Without the "pull" of rewards, people with high SA may fail to engage in this adaptive repair process.

Another factor contributing to differences between people with high versus low SA in responding to social exclusion may be related to whether social exclusion piques feelings of curiosity, which in turn drives the desire for additional information. Supporting this idea is the notion that social exclusion is often painful precisely because it is unexpected (Wesselmann et al., 2017). People tend to hold expectations about their relational value based on their potential to develop meaningful interpersonal connections with others and on others' reciprocal desire for relational closeness with them; therefore, when someone behaves in a manner that violates these expectations-known as "relational devaluation"-people experience social pain, alerting them to initiate the social repair process (Leary \& Springer, 2000; Leary et al., 1998). This powerful emotional signal that alerts a discrepancy between expectations and reality may be conceptualized as a form of prediction error, which elevates people's curiosity and enhances their motivation to resolve the discrepancy by seeking further information, ultimately driving them toward the interpersonal and emotional rewards associated with social reconnection (Gruber \& Ranganath, 2019).

It is possible that social exclusion fails to pique high SA individuals' curiosity to seek additional information through social reconnection because they expect to be rejected or excluded and therefore do not experience prediction error when their expectations are supported. Moreover, research has shown that curiosity only prompts exploration when the 
cause of the prediction error is appraised to be manageable (Gruber \& Ranganath, 2019), and those with high SA may find the problem insurmountable due to their perception of themselves as having poor social competency (see Moscovitch, 2009; Rodebaugh, 2009). In summary, in the face of a threatening social exclusion, those with higher SA may be less likely to shift into a state of curiosity-driven appetitive goal pursuit, recognize social reward potential, and experience a heightened desire to affiliate.

\section{Current Study Objectives and Hypotheses}

The current study sought to investigate (a) whether heightened affiliation in the face of painful exclusion promotes heightened downstream positive affect, (b) whether a goalpursuit mechanism involving curiosity and reward recognition facilitates this process, and (c) whether and how these repair processes may become disrupted for those with higher trait levels of SA. We investigated these research questions by testing one primary model and two exploratory ones, as described below.

We created an online experiment and recruited a sample of community participants in which participants were first randomly assigned to 1 of 2 conditions where they were either rejected or included and then provided with a subsequent opportunity to engage with avatars whom they were led to believe were other online participants. Proposed mechanisms were assessed via self-report measures that were administered in sequential fashion. This study was preregistered on the Open Science Framework website at https://osf.io/vc9fs/.

\section{Primary Model}

Our primary goal was to test a consecutive mediation model ${ }^{1}$ in which we predicted that exclusion (relative to inclusion) would lead to greater social pain, which would in turn increase social approach motivation, and finally enhance downstream positive affect. The variables and proposed relationships for this model were determined a-priori and outlined in our study pre-registration materials. The

\footnotetext{
${ }^{1}$ Consecutive (or serial) mediation represents a causal chain, whereby predictor variable $\mathrm{X}$ is hypothesized to have a causal impact on mediator variable 1 , which then subsequently causes an impact on mediator variable 2 , and finally, mediator 2 impacts outcome variable $\mathrm{Y}(\mathrm{X} \rightarrow \mathrm{M} 1 \rightarrow \mathrm{M} 2 \rightarrow \mathrm{Y}$ ). This process differs from simultaneous (or concurrent) mediation, which implies that predictor variable $\mathrm{X}$ has a direct impact on 2 or more mediator variables at once, and subsequently, all mediator variables have a direct impact on outcome variable $\mathrm{Y}$ at once $(\mathrm{X} \rightarrow \mathrm{M} 1 \& \mathrm{M} 2 \rightarrow \mathrm{Y}$ ) (Hayes, 2017).
}

theoretical foundation for this model and the basic relationships between its factors were originally examined in Hudd and Moscovitch (2020), and the present study was designed to build upon and extend those preliminary findings.

\section{Hypothesized SA Moderation Effect}

We further predicted that this consecutive mediation effect would be moderated by trait SA, such that only those with low but not high levels of SA would respond to the pain of exclusion with increased desire to approach and heightened positive affect. However, doubling the sample size to achieve the necessary power to detect significant moderated mediation effects (as suggested by Simonsohn, 2014) was financially unfeasible if we also wished to give participants a fair wage, which is dictated by Prolific policy as a minimum of $\$ 6.50$ USD per hour. Thus, consecutive mediation was conceptualized as the primary research question, for which our study was intentionally powered (see Sample Size and Power Calculations below). Nonetheless, we still pursued exploration of the moderated mediation effect in order to: (1) observe variability in the strength of the consecutive mediation effect across levels of SA at a descriptive level, knowing it was unlikely to meet $p$-value threshold for significance, and (2) observe the simple moderation effect between SA and social pain for predicting social approach motivation, which we were sufficiently powered to observe and interpret.

Furthermore, we planned to compare this model with and without current depressive symptoms entered as a covariate. We sought to ensure effects pertaining to trait SA would not be explained by concurrent low mood, as SA and dysphoria often present comorbidly (Moitra et al., 2008) and low mood could be reasonably expected to affect each variable of interest. Others have taken a similar approach when examining the effects of SA on social affiliation (Mallott et al., 2009).

\section{Exploratory Models}

We also aimed to test two exploratory mediation models that investigated the effects of curiosity as well as reward and threat anticipation and perception on social approach motivation. The theoretical foundation for investigating these variables was first discussed in Hudd and Moscovitch (2020), where it was theorized that goal-pursuit and heightened reward perception might explain motivation to affiliate in the face of painful exclusion, and that SA symptoms would likely moderate this effect. However, the roles of curiosity and reward and threat variables were only theorized in Hudd and Moscovitch (2020) and not measured or examined directly. 


\section{Exploratory Model 1}

Our first exploratory model was that social pain would predict heightened curiosity and, in turn, increased perception of social rewards and heightened approach motivation for subsequent social activities (social pain $\rightarrow$ curiosity $\rightarrow$ reward perception $\rightarrow$ approach motivation). We hypothesized that this effect may be moderated by trait SA in two possible ways: that in response to higher levels of social pain, those with high SA would either (a) experience lower levels of curiosity and/or (b) perceive fewer social rewards. ${ }^{2}$ As in the primary model, we only expected to have sufficient power to detect the consecutive mediation effect, but not the moderated consecutive mediation effect. Once again, we included the moderated mediation effects in the model because we intended to observe variability in the strength of consecutive mediation effect across levels of SA at a descriptive level as well as interpreting the sufficiently powered simple moderation effects between SA and social pain for predicting curiosity and social reward perception. We again sought to compare the effects of this model with and without depressive symptoms entered as a covariate to distinguish the effects of trait SA from the potential effects of low mood.

\section{Exploratory Model 2}

In the second exploratory model, we aimed to investigate the potential roles of social reward and threat perception in the relationship between SA and dampened approach motivation. Specifically, we sought to investigate the relative strength of anticipated or perceived rewards versus anticipated or perceived threats as simultaneous mediators of the relationship between SA and approach motivation (social anxiety $\rightarrow$ reward anticipation, reward perception, threat anticipation \& threat perception $\rightarrow$ approach motivation). These effects were also compared with and without depressive symptoms entered as a covariate in the model.

\section{Methods}

\section{Participants}

The sample consisted of participants recruited from the Prolific research participation pool. ${ }^{3,4}$ We restricted the sample to those residing in the United States or Canada. Participants were removed from the original collected sample of $N=470$ if they: (a) did not properly indicate their consent to participate $(n=8)$, (b) entered the study, quit, and then re-entered, as this may have compromised the integrity of their data $(n=9)$, or (c) if they did not reconsent after being debriefed about the study's deceptions $(n=1)$. Participants were also removed if they failed to adequately meet selfreported and embedded attention checks. Adequate attention was determined using two methods. First, a summary score was created for participants' self-reported attention and honesty (minimum possible score of 3 , maximum possible score of 15). The distribution of scores revealed that most participants scored 10 and above $(98.7 \%)$. Those who scored $<10$ on the self-report attention/honesty check $(n=6)$ were flagged for further review. Participants who were flagged for lower scores on the attention/honesty measure $(n=6)$ were examined to see how they performed on the embedded attention checks. Most of these participants passed all embedded attention checks: only one participant failed any of the embedded attention checks, and in this case, they still passed the majority ( 4 out of 6 checks). In the entire sample, $87 \%$ of the participants passed all 6 embedded attention checks. Based on these results, we determined that all participants demonstrated sufficient attention and honest engagement.

Exclusions resulted in a final sample of $N=452$. Participants were, on average, 33.77 years old $(S D=12.20)$, with $52.9 \%$ identifying as male, $46.5 \%$ identifying as female, and $0.7 \%$ identifying as non-binary. The sample primarily consisted of participants residing in the United States (81\%), while the remainder were Canadian (19\%). Most participants had completed all or part of a professional degree (98.3\%), some held a high school diploma (11.3\%), while very few had not completed high school $(0.4 \%)$.

Participants from Canada $(n=86)$ identified their cultural/ethnic background as follows: Asian (38\%), European (31.4\%), other North American (12.8\%), African (7.0\%), prefer to self-identify (3.5\%), prefer not to answer (3.5\%),

\footnotetext{
${ }^{3}$ Our study pre-registration stated that participants would be recruited from MTurk, but due to concerns about the increasing prevalence of bot data on the MTurk platform, especially during the start of the COVID-19 pandemic when the study was preparing to launch, we opted instead to use the Prolific platform for recruitment. We discovered zero evidence of bot data in our study sample.

${ }^{4}$ Prolific is an online platform that allows researchers to connect with potential research participants in exchange for remuneration.
}

\footnotetext{
${ }^{2}$ It is worth noting that the effects of condition were not accounted for in this model. The focal predictor of this model is social pain, which (in accordance with primary hypothesis 1 ) is expected to vary as a function of condition. In this analysis we retained all participants across both the inclusion and exclusion conditions to allow for maximum variability in our focal predictor (social pain) by including participants who experienced lower levels of social pain (i.e., those within the inclusion condition), and to retain maximum power for detecting anticipated effects.
} 


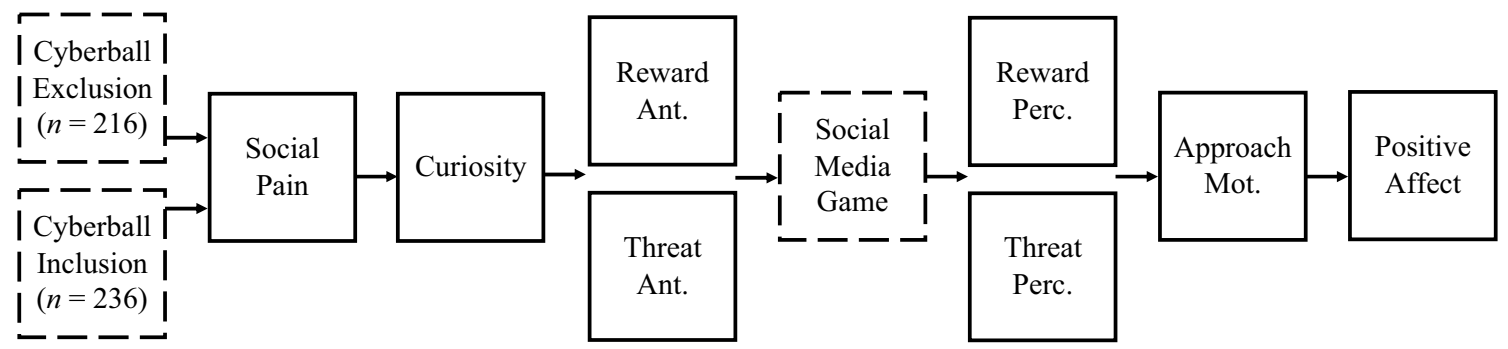

Fig. 1 Visual representation of study procedures. Note Boxes with dotted lines represent the two activities to which participants were exposed during the study. Solid lines represent measures collected from participants

Caribbean (2.3\%), Indigenous (2.3\%), and Metis (1.2\%). Those who preferred to self-identify $(n=3)$ described themselves as South Asian, North African and Black American. Participants from the United States $(n=366)$ identified their cultural/ethnic background as follows: White or European American (71.9\%), Asian (14.2\%), Black or African American $(8.7 \%)$, Hispanic Latinx (7.4\%), prefer to self-identify (1.6\%), Indigenous or Alaskan Native (1.4\%), Non-Hispanic Latinx $(0.8 \%)$, and prefer not to answer $(0.3 \%)$. Those who preferred to self-identify $(n=4)$ described themselves as Ashkenazi Jewish, Mixed, Native American, or White/West Asian.

\section{Sample Size and Power Calculations}

The target sample size was calculated based on the necessary power required to detect effects within the primary consecutive mediation model. Expected effects ranged from small to large and were estimated based on correlations reported in Hudd and Moscovitch (2020) between very similar (or identical) variables of interest for the present study. Specifically, we estimated the effect of condition on social pain to be medium-large $(r=.45)$ while its direct effects on social approach motivation and positive affect were estimated to be small ( $r=.04$ and .17 , respectively). We estimated the relationship between social pain and approach motivation (without accounting for trait SA moderation effects) to be small $(r=.14)$, and the relationship between social pain and positive affect to be medium ( $r=.38$ ). Finally, we estimated the relationship between approach motivation and positive affect to be large $(r=.42)$. These were entered into a Monte Carlo power analysis for indirect effects (Schoemann et al., 2017), which estimated that in order to detect a significant serial mediation effect in the primary analysis with .80 power, we would require a sample size of approximately $N=433$.

\section{Overview of Study Procedures}

The study took place entirely online. At the beginning of the study, participants were told that they would complete several activities online with other Prolific participants, when in fact each participant was the only participant involved and all interactions with others were with pre-programmed avatars. Participants completed trait and demographic questionnaires and then were randomly assigned to one of two conditions in which they experienced social exclusion or social inclusion during a game of Cyberball.

After the Cyberball game, participants completed a measure of social pain and then state curiosity. Then, all participants across conditions were told about two upcoming social interaction activities. They were informed that they would first participate in a social media task (described below) and then later have the chance to interact via instant messaging with one other participant in a final social task. In reality, participants would only participate in the Cyberball and social media task, but not the "instant messaging" task. The instant messaging task was only introduced as a potential upcoming social activity so we could first measure anticipated and perceived rewards and threats within the context of the social media activity and then evaluate how this affected the degree to which participants were interested in further affiliating with others.

After Cyberball, participants were informed of the upcoming social media task and asked to rate to what degree they anticipated experiencing social rewards or threats in that task. Participants then completed the social media activity and, immediately afterward, rated their perception of social rewards and threats within the social media task itself. Subsequently, participants were reminded of the final ostensible social interaction task ("instant messaging") and rated their degree of motivation to engage with others in this activity. Finally, they completed a measure of state positive affect, were debriefed about the study purpose and deceptions, and were given the opportunity to provide confirmation that they consented to our use of their data. The study took approximately $30 \mathrm{~min}$ to complete. Figure 1 provides a visual representation of study procedures.

\section{Cyberball Procedures}

Participants in both the exclusion and inclusion conditions participated in a game of Cyberball with 3 other players for a 
minimum of 2 min (36 total throws). To enhance the believability of the deception and establish a sense of personal identity and connection among the players, all players were asked to send a message to the group at the beginning of the game in which they introduced themselves and their favourite book or movie. Because participants were led to believe the other ostensible players received the same prompt, the avatars were programmed to also send a message introducing themselves and their favourite book or movie. Participants assigned to be excluded received 3 passes at the beginning of the game and then zero passes for the remainder of the game, while those assigned to be included received the same number of passes as the other avatars on screen.

\section{Social Interaction Activity}

After responding to the social pain measure, participants anticipated engaging in a social media interaction activity. This activity was designed to provide a social context within which participants could anticipate and perceive social rewards or threats. Drawing upon a paradigm originally used by Wolf et al. (2015), we deceived study participants to believe that they would be interacting in an online space with other participants whose profiles they could see (in reality, these were preprogrammed avatars). They were instructed to write their own personal profile and were then exposed to the profiles of 10 other avatars, who were described as university students with diverse backgrounds, hobbies, and interests. We informed participants that in the first part of the task, they were to read and click "like" on as many profiles as they wished. Participants were pre-programmed to receive 5 total "likes" (out of a possible 10) and the pre-programmed profiles were also programmed to receive between 4 and 5 "likes", in addition to whatever the real participant chose to give. By keeping the number of "likes" relatively equal between the participant and the other ostensible participants, the context was left neutral and ambiguous (neither overt inclusion nor exclusion).

\section{Manipulation Checks}

We used two pre-validated measures to serve as Cyberball condition manipulation checks. First, participants responded to a two-item manipulation check to ensure they recognized that they were thrown the ball equally or far fewer times relative to the other players. They were asked to rate the following items on a 5-point Likert scale ranging from 1 (no, not at all) to 5 (yes, definitely): I was thrown the ball less frequently than the other players, and I received the ball just as frequently as the other players. This manipulation check was validated in a previous study (Hudd \& Moscovitch, 2020). Participants also completed the Needs-Threat Scale (NTS; Williams et al., 2000), which was developed based on theory and data that suggest social exclusion threatens a core set of fundamental human needs. Thus, we used this measure to ensure our exclusion manipulation generated expected psychological "threat" responses across the theorized domains, including needs for belongingness (e.g., I felt like an outsider during the Cyberball game), self-esteem (e.g., During the Cyberball game, I felt good about myself), control (e.g., I felt in control during the Cyberball game), and meaning (e.g., I felt as though my existence was meaningless during the Cyberball game). For this measure, participants rated their agreement with items on a 9-point Likert scale ranging from 1 (not at all) to 9 (very much). The Needs-Threat scale items revealed good internal consistency, $\alpha=.90$.

\section{Trait Measures}

\section{Social Anxiety Symptoms}

The Social Phobia Inventory (SPIN; Connor et al., 2000), which served as our measure of trait SA, includes 17 items that measure SA symptoms over the past week. The SPIN has demonstrated strong reliability and validity in prior research (Connor et al., 2000) and showed good internal consistency in the current study $(\alpha=.94)$.

\section{Depressive Symptoms}

The Depression Anxiety and Stress Scales (DASS; Lovibond \& Lovibond, 1995) is a 21-item questionnaire assessing symptoms of depression, anxiety, and stress over the past week. Only the DASS items pertaining to symptoms of depression, of which there are seven items (e.g., "I felt down-hearted and blue"), were used for this study. This measure has shown good internal consistency, validity and support for its 3-factor structure (Page et al., 2007) and demonstrated good internal consistency in the current study $(\alpha=.93)$.

\section{State Measures}

\section{Social Pain}

Participants responded to this measure immediately after the condition task and were asked to rate items describing how they felt "just now, while completing the activity" on a Likert scale ranging from 1 (very slightly or not at all) to 5 (extremely). Researchers have used a wide variety of social pain measures that tend to capture psychological or emotional distress and some form of rejection appraisal (e.g., Auyeung \& Alden, 2016; Chester et al., 2016; Nordgren et al., 2011; Zadro et al., 2004). Hudd and Moscovitch (2020) used a composite measure of negative affect and additional items that captured the notion of being rejected or 
excluded as their measure of social pain. As such, we used the same approach by collecting responses from the Positive and Negative Affect Schedule (PANAS; Watson et al., 1988), and responses to following two additional items: "I felt rejected" and "I felt excluded". The items were combined to form a composite measure with negative affect, which had good internal consistency, $\alpha=.87$.

\section{Curiosity}

Participants responded to the curiosity measure after completing the social pain measure. They were asked to rate 6 items describing how they felt "just now, while completing the game of catch" on a Likert scale ranging from 1 (not at all) to 5 (very much so). We used a shortened, adapted version of the state measure of the State-Trait Curiosity Inventory (Naylor, 1981). This was done an effort to limit response fatigue and potential agitation we anticipated participants might experience if asked to respond to the full 21 -item measure. For the present study, the following items were included, which sought to capture participants' feelings of surprise, intrigue, and desire to pursue more information: I felt curious about what was happening; I was feeling puzzled; My curiosity was aroused; I felt like searching for answers; I felt absorbed in what I was doing; and My interest was captured. These items revealed satisfactory internal consistency, $\alpha=.79$.

\section{Positive Affect}

At the end of the study, participants completed the state positive affect subscale of the Positive and Negative Affect Schedule (PANAS; Watson et al., 1988) consisting of emotion adjectives rated on a 5-point Likert scale, such as "interested," "excited," and "enthusiastic." The positive affect subscale demonstrated good reliability $(\alpha=.97)$.

\section{Social Approach Motivation}

Participants were asked to rate the following items on a scale from 1 to 9: I am eager to learn more about another participant, I am excited to interact with someone, and I am looking forward to sharing more about myself, and I would prefer not to further interact with anyone (reverse-coded). This measure demonstrated good reliability $(\alpha=.93)$.

\section{Social Reward and Threat Scales}

Social reward and threat scales were devised to capture the degree to which participants anticipated the social media activity would be socially rewarding and threatening (social reward and threat anticipation) and, after the task, to capture the degree to which participants perceived the social media activity as having been socially rewarding and threatening (social reward and threat perception). See Supplementary Materials for details about the development of reward and threat scales and the psychometric analyses used to support their discriminant validity.

\section{Social Reward Anticipation (Pre-social Media Task)}

Participants were asked to rate the following items on a scale from 1 to 9: Others will enjoy reading my profile; I will feel good sharing information about myself with others; I will discover that I share common interests with other participants; based on my profile, other participants will think positively about me; participants on the social media platform will accept me; and I will enjoy connecting with others through this online activity. This measure demonstrated good reliability $(\alpha=.92)$.

\section{Social Reward Perception (Post-social Media Task)}

Participants were asked to rate the following items on a scale from 1 to 9: Others enjoyed reading my profile; I felt good sharing information about myself with others; I discovered that I shared common interests with other participants; based on my profile other participants probably thought positively of me; participants on the social media platform appear to have accepted me; and I enjoyed connecting with others through this online activity. This measure demonstrated good reliability $(\alpha=.89)$.

\section{Social Threat Anticipation (Pre-social Media Task)}

Participants were asked to rate the following items on a scale from 1 to 9: Other participants will dislike my profile; Sharing information about myself will make me feel inferior to others; I will feel like an outsider during this task; Based on my profile, other participants will think poorly of me; Other participants will ignore my profile; and Participants on the social media platform won't be interested in connecting with $m e$. This measure demonstrated good reliability $(\alpha=.89)$.

\section{Social Threat Perception (Post-social Media Task)}

Participants were asked to rate the following items on a scale from 1 to 9: Other participants disliked my profile; Sharing information about myself made me feel inferior to others; I felt like an outsider during this task; Based on my profile, other participants probably thought poorly of me; Other participants ignored my profile; and Participants on the social media platform probably won't be interested in connecting with me in the next activity. This measure demonstrated good reliability $(\alpha=.85)$. 


\section{Data Analytic Plan for Primary Hypothesis}

Data were analyzed with the Hayes PROCESS macro developed for SPSS (Hayes, 2017). Hayes PROCESS examines both the direct effects and $R^{2}$ change values for interaction effects, in addition to providing bias corrected bootstrap confidence intervals based on 5000 bootstrap samples. We sought to follow-up on any significant interaction effects by probing for simple effects at $1 S D$ at, above, and below the mean of the moderator variable.

Using Hayes PROCESS model 91, we tested the preregistered moderated consecutive mediator model by entering condition (exclusion vs. inclusion) as the predictor variable (X), social pain (M1) and approach motivation (M2) as the consecutive mediators, and positive affect (Y) as the outcome variable. Trait SA was entered as a moderator between social pain (M1) and social approach (M2), as depicted in Figure S1 in the Supplementary Materials. The model was run with and without depression entered as a covariate in the model.

\section{Data Analytic Plan for Exploratory Hypotheses}

With Hayes PROCESS model 84, we tested the first exploratory model, which also consisted of a moderated consecutive mediator model. As shown in Figure S2 in the Supplementary Materials, social pain was entered as the predictor variable (X), curiosity (M1) and reward perception (M2) as the consecutive mediators, and approach motivation (Y) as the outcome variable. Trait SA was entered as a moderator between social pain (X) and curiosity (M1), as well as between social pain (X) and reward perception (M2). This model was also run with and without depression entered as a covariate in the model.

Finally, with Hayes PROCESS model 4, we used a simultaneous mediation model by entering SA as the predictor variable $(\mathrm{X})$, and reward anticipation (M1), reward perception (M2), threat anticipation (M3), and threat perception (M4) as the simultaneous mediators, with approach motivation (Y) as the outcome variable. See Figure S3 in the Supplementary Materials. Once again, this model was run with and without depression entered as a covariate in the model.

\section{Results}

Means, standard deviations and bivariate correlations between variables - both within and collapsed across conditions-are provided in the Supplementary Materials in Tables S1, S2 and S3.

\section{Missing Data and Outlier Analyses}

Most measures had no missing data, and those that did had very little missing data, with a maximum of $0.7 \%$ missing data per item. Missing data across measures were considered MCAR based on non-significant Little's MCAR tests. Missing data were imputed using the expectation-maximization approach whenever the majority of items were completed for a particular scale. Data points were deleted listwise from analyses in instances when the majority of items for a particular scale were missing. Data were visually scanned for outliers using boxplots and descriptive analyses, and no data points were excluded as outliers. All measures were normally distributed, with skewness and kurtosis less than 3 and greater than -3 for each measure.

\section{Manipulation Checks}

Compared to participants in the inclusion condition, those assigned to the exclusion condition were more likely to respond that they received the ball less frequently relative to the other players, $t(450)=20.307, p<.001$, CI of $M$ difference [2.09, 2.54], and less likely to respond that they received the ball an equal number of times relative to the other players $t(450)=-22.186, p<.001$, CI $[-2.58$, $-2.16]$. Moreover, those in the exclusion condition reported higher ratings on the Needs-Threat Scale, $t(450)=16.026$, $p<.001$, CI of $M$ difference [23.42, 29.96].

\section{Trait Social Anxiety Measure}

Participants represented a normally distributed range of SA symptoms $(M=26.44, S D=15.01)$. As shown in Table $\mathrm{S} 1$, scores were similar across conditions.

\section{Depression Covariate}

Findings from each of the three models did not change meaningfully when depression was entered as a covariate. As such, results reflect iterations of each model where depression was not included as a covariate.

\section{Primary Analysis: Does the Pain of Social Exclusion Promote Heightened Social Approach Motivation and Positive Affect, but Only at Low Levels of SA?}

Results demonstrated that the proposed conditional indirect effect was non-significant, index $=.04, \mathrm{SE}=.04$, CI $[-.11$, .04]. However, the consecutive mediation effect was significant. In other words, the relationship between condition (X) and positive affect (Y) was mediated by social pain (M1) and approach motivation (M2), but this consecutive indirect effect was not moderated by trait SA. The indirect effect was 
Fig. 2 Direct effects in the primary analysis. Note Box with dotted lines represents the interaction term (social anxiety $\times$ social pain)

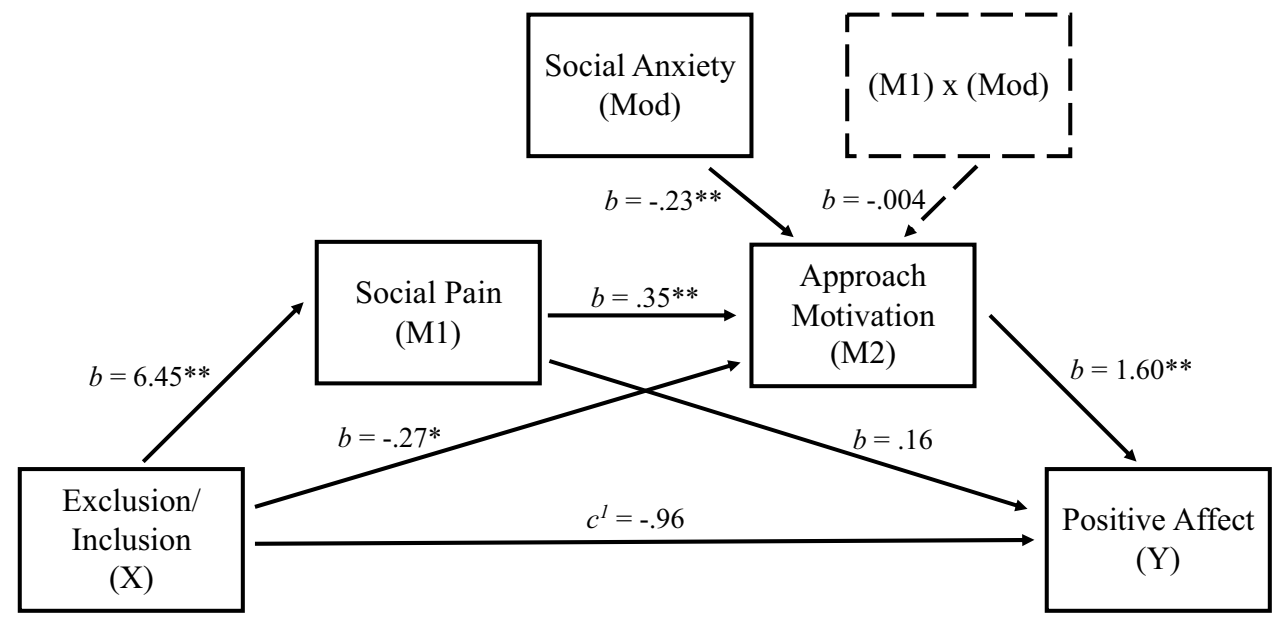

significant at all levels of SA: low, $b=4.18, \mathrm{SE}=1.26, \mathrm{CI}$ $[1.83,6.68]$, average $b=3.61, \mathrm{SE}=.83$, CI $[2.08,5.36]$ and high, $b=3.01, \mathrm{SE}=.77$, CI $[1.60,4.56]$. The findings for each step of the model are reported below and in Fig. 2.

In the first step of the model, condition predicted significant variability in social pain, $R^{2}=.16, F(1,449)=82.512, p<.001$, such that those who were excluded felt more social pain.

In the second step, condition, social pain, SA and the interaction between social pain and SA collectively predicted significant variability in approach motivation, $R^{2}=12, F(4$, $446)=15.020, p<.001$. Of these, condition, social pain and SA each predicted unique variability in approach motivation. Those who were included reported higher approach motivation, $b=-2.70, \mathrm{SE}=1.0, p=.007$, CI $[-4.66,-0.73]$, as did those who reported higher levels of social pain, $b=.35$, $\mathrm{SE}=.07, p<.001, \mathrm{CI}[.21, .49]$, whereas high trait SA predicted lower approach motivation, $b=-.23, \mathrm{SE}=.03$, $p<.001$, CI $[-.30,-.17]$. The interaction between social pain and SA was non-significant, $b=-.004, \mathrm{SE}=.004$, $p=.320$, CI $[-.01, .003]$.

Finally, in the third step, condition, social pain, and approach motivation collectively predicted significant variability in positive affect, $R^{2}=.48, F(3,447)=134.806$, $p<.001$. Of these, only approach motivation exhibited a direct relationship with positive affect, $b=1.60, \mathrm{SE}=.08$, $p<.001$, CI [1.44, 1.76], while the direct effects of condition, $b=-.96, \mathrm{SE}=1.76, p=.589$, CI $[-4.42,2.51]$ and social pain, $b=.16, \mathrm{SE}=.11, p=.145, \mathrm{CI}[-.05, .37]$, did not.

\section{Exploratory Analysis 1: Does Social Pain Promote Curiosity, Leading to Heightened Social Reward Perception and Social Approach Motivation, but Only at Low Levels of SA?}

Results demonstrated that the proposed conditional indirect effect was non-significant, index $=-.001, \mathrm{SE}=.001, \mathrm{CI}$
$[-.003, .001]$. However, the consecutive mediation effect was significant. In other words, the relationship between social pain $(\mathrm{X})$ and approach motivation $(\mathrm{Y})$ was mediated by curiosity (M1) and reward perception (M2), but this indirect effect was not moderated by trait $\mathrm{SA}$. The indirect effect was significant at all levels of SA: low, $b=.13, \mathrm{SE}=.03, \mathrm{CI}$ $[.07, .19]$, average, $b=.11, \mathrm{SE}=.02$, CI $[.07, .15]$ and high, $b=.09, \mathrm{SE}=.02, \mathrm{CI}[.06, .13]$. The findings for each step of the model are reported below and presented in Fig. 3.

In the first step of the model, social pain, SA and their interaction term collectively predicted significant variability in curiosity, $R^{2}=.10, F(3,447)=16.793, p<.001$. Those who experienced higher social pain reported greater curiosity, $b=.17, \mathrm{SE}=.03, p<.001$, CI $[.12, .22]$, while individuals with higher trait SA reported lower overall curiosity, $b=-.03, \mathrm{SE}=.01, p=.022$, CI $[-.05,-.004]$. However, the interaction between social pain and SA did not predict significant variability in curiosity, $b=-.001, \mathrm{SE}=.001$, $p=.278$, CI $[-.004, .001]$.

In the second step, social pain, curiosity, SA and the interaction between social pain and SA collectively predicted significant variability in reward perception, $R^{2}=.20, F(4$, $446)=27.836, p<.001$. Of these, only curiosity and SA demonstrated significant direct relationships with approach motivation: those who were more curious perceived more social rewards, $b=1.0, \mathrm{SE}=.12, p<.001$, CI [.77, 1.24], while those with higher trait SA perceived fewer social rewards, $b=-.15, \mathrm{SE}=.03, p<.001$, CI $[-.21,-.10]$. The direct relationship between social pain and reward perception was non-significant, $b=.02, \mathrm{SE}=.07, p=.683, \mathrm{CI}$ $[-.10, .16]$, as was the interaction effect between social pain and SA on reward perception, $b=.001, \mathrm{SE}=.003, p=.856$, CI $[-.01, .01]$.

Finally, in the third step, social pain, curiosity and reward perception collectively predicted significant variability in approach motivation, $R^{2}=.45, F(3,447)=121.814, p<.001$. Higher reward perception predicted greater approach 
Fig. 3 Direct effects in exploratory model 1 . Note Boxes with dotted lines represent the interaction term (social anxiety $\times$ social pain)

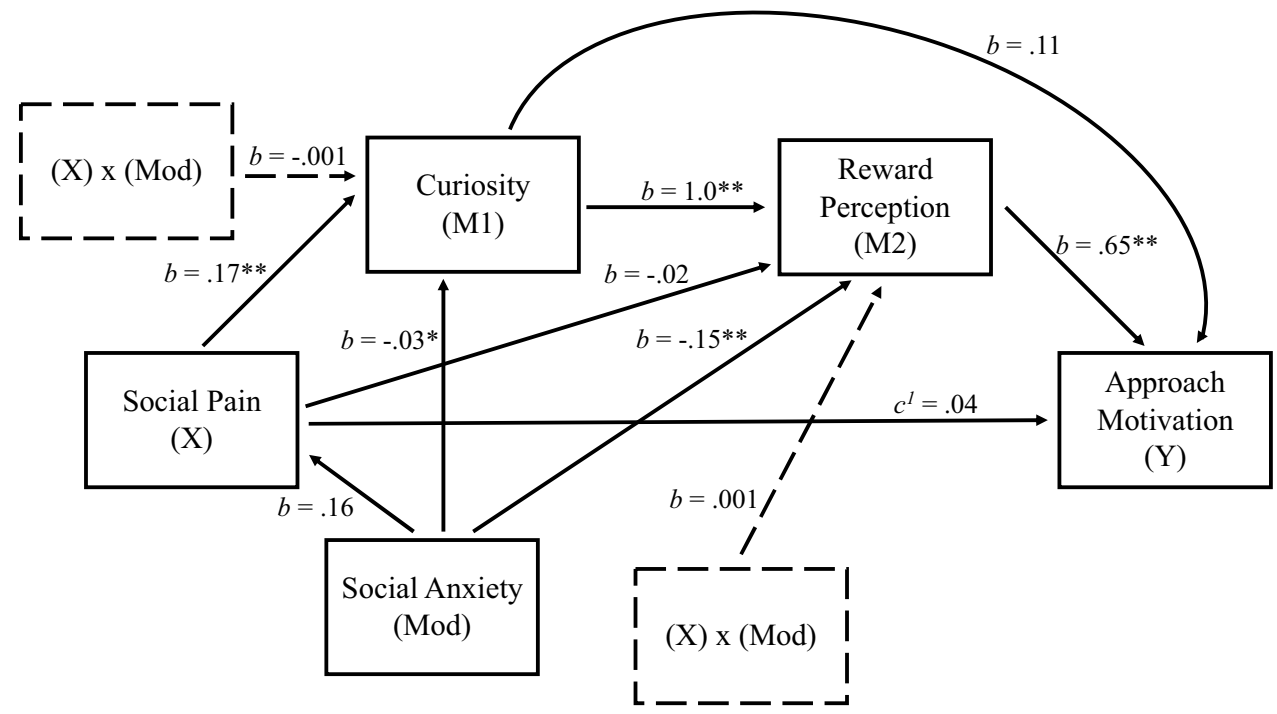

motivation, $b=.65, \mathrm{SE}=.04, p<.001$, CI $[.58, .73]$. However, the direct effects of both social pain, $b=.04, \mathrm{SE}=.05$, $p=.322$, CI $[-.04, .13]$, and curiosity, $b=.11, \mathrm{SE}=.11$, $p=.299$, CI $[-.10, .32]$, were non-significant.

\section{Exploratory Analysis 2: Do Anticipated and Perceived Social Reward and Threat Explain the Relationship Between Social Anxiety and Social Approach Motivation?}

Results showed that anticipated and perceived social rewards significantly mediated the relationship between SA and approach motivation, $b=-.08, \mathrm{SE}=.02, \mathrm{CI}[-.11,-.05]$, and $b=-.06, \mathrm{SE}=.02, \mathrm{CI}[-.09,-.03]$, respectively, but anticipated and perceived social threat did not predict additional, significant variability beyond what was accounted for by the reward measures, $b=-.03, \mathrm{SE}=.02$, CI $[-.07$, $.003]$, and $b=.02, \mathrm{SE}=.01$, CI $[-.01, .05]$, respectively. The findings for each step of the model are reported below and presented in Fig. 4.

SA predicted significant variability in each of the mediator variables, including reward anticipation, $R^{2}=.11, F(1$, $449)=58.115, p<.001$, reward perception, $R^{2}=.05, F(4$, $449)=23.101, p<.001$, threat anticipation, $R^{2}=.27, F(4$, $449)=166.791, p<.001$, and threat perception, $R^{2}=.17$, $F(4,449)=94.624, p<.001$.

With all mediators in the model concurrently, only anticipated and perceived rewards were significantly related to approach motivation, $b=.31, \mathrm{SE}=.05, p<.001, \mathrm{CI}[.21, .40]$ and $b=.41, \mathrm{SE}=.05, p<.001, \mathrm{CI}[.31,51]$, whereas anticipated and perceived threat were only marginally and nonsignificantly related to approach motivation, respectively: $b=-.09, \mathrm{SE}=.04, p=.054, \mathrm{CI}[-.17, .002]$ and $b=.07$, $\mathrm{SE}=.05, p=.180, \mathrm{CI}[-.03, .17]$.
Finally, with the effects of reward and threat mediators accounted for, SA was no longer directly associated with approach motivation, $b=-.02, \mathrm{SE}=.03, p=.374, \mathrm{CI}[-.08$, $.03]$.

\section{Discussion}

The current study sought to investigate the mechanisms that promote heightened affiliation in the face of painful exclusion, and to examine how the social repair process may be disrupted for those with higher levels of trait SA. Within an online context, participants were first made to first feel rejected or included, and then provided with an opportunity to engage with others. We tested one primary mediation model and two exploratory mediation models in a wellpowered sample of community participants. These models

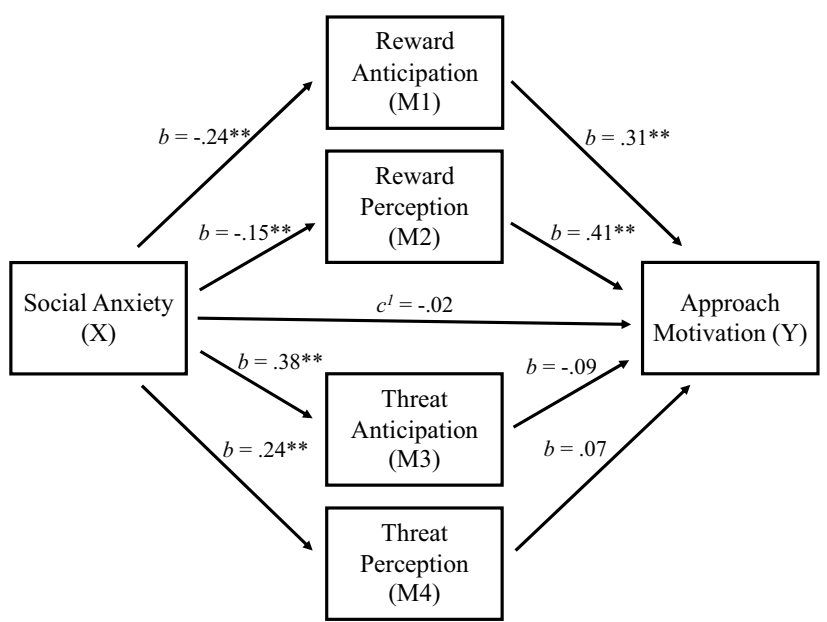

Fig. 4 Direct effects in exploratory model 2 
were derived from hypotheses originally proposed in Hudd and Moscovitch (2020), which specified how social pain and social approach processes may work together to facilitate social and emotional repair in the face of social pain, and how these processes may be impacted by trait SA.

\section{Results of the Primary Model}

We predicted that following social exclusion, heightened feelings of social pain would enhance the desire to reconnect with others and, in turn, would elevate feelings of positive affect. We also expected that individuals with higher levels of SA would respond to their social pain with attenuated desire to approach, thus inhibiting the social repair process. Results supported the proposed consecutive mediation effect at all levels of SA, suggesting that heightened desire to approach in the face of painful exclusion was associated with downstream positive affect. The simple interaction between SA and social pain for predicting social approach motivation was non-significant. Including current depressive symptoms as a covariate had no meaningful impact on results.

\section{Results of the Exploratory Models}

Next, we tested two exploratory models that were designed to improve our understanding of the cognitive mechanisms that might link heightened social pain with an increased desire to reconnect with others. In the first model, we expected greater social pain to predict heightened curiosity, leading to greater perception of social rewards and, in turn, an increased desire to engage in a subsequent social task. Again, we explored whether this effect would be moderated by trait SA in one of two ways, such that only those at lower levels of SA would respond to their social pain with heightened curiosity and/or reward perception. Results supported the proposed consecutive mediation effect at all levels of SA, suggesting curiosity in the face of social pain was associated with heightened reward perception and greater downstream approach motivation. As in the primary analysis, the simple interaction effects revealed that SA did not moderate the effect of social pain on curiosity, nor did it moderate the effect of social pain on reward perception.

Since diminished approach motivation has long been conceptualized as a critical problem for individuals with SAD that may account for deficits in positive interpersonal and emotional experiences (e.g., Kashdan, 2007; Richey et al., 2014), our second exploratory model was designed to investigate potential mediators of the relationship between SA and approach motivation. Specifically, we tested whether heightened social threat appraisals and/or diminished social reward appraisals may link higher trait SA with lower approach motivations when individuals are faced with opportunities to engage socially with others. Findings revealed that reward anticipation and perception mediated the relationship between SA and approach motivation, over and above the effects of threat anticipation and perception. In other words, threat anticipation and perception had no significant predictive value beyond the effects of reward anticipation and perception.

\section{Impact of Trait SA on Social Repair Processes}

For those with lower levels of SA, the consecutive mediation effects in the primary analysis and first exploratory model revealed social repair processes that appeared to reflect a state of goal pursuit, which conferred short-term social and mood benefits. For low SA participants, higher social pain was associated with greater curiosity, which in turn predicted greater recognition of socially rewarding information. In contrast, findings from all three models suggested that high SA participants exhibited low desire to pursue social connections, perhaps due to dampened social reward expectations and perceptions. The simple interaction effects between social pain and SA on social approach motivation and reward perception were sufficiently powered and found to be non-significant with effect sizes that were quite small, suggesting that challenges in initiating social repair processes for those with high SA may be unrelated to the strength of the pain signal, or may occur further downstream in the repair process. Indeed, individuals with high SA may have entered the study expecting that affiliative contexts are unlikely to be rewarding or enjoyable, thereby dampening their desire to connect with others irrespective of how painful their experience during Cyberball may have felt. Given their pessimistic expectations, higher SA individuals may never have experienced the kind of prediction error that is hypothesized to generate affiliative goal pursuit in the aftermath of social pain. In contrast, if low SA participants entered the Cyberball context expecting to be included, attending with curiosity to socially positive and rewarding information in the face of social pain may have been the most efficient route for resolving the initial prediction error.

The association between high SA and dampened social reward responsivity is consistent with evidence that suggests individuals with high SA have difficulty recognizing, appreciating, and retaining socially rewarding information. Prior research has found that people with high SA tend to discount positive social information, even if positive social feedback is explicit and unambiguous (Koban et al., 2017; Vassilopoulos \& Banerjee, 2010). In fact, people with high SA tend to fear positive social feedback (Weeks \& Howell, 2012). Even in contexts in which socially rewarding information is initially recognized, the perceived positivity of such information tends to degrade uniquely over time in the memories of high SA individuals specifically (Glazier \& Alden, 2019; Romano et al., 2020). 


\section{Study Limitations}

The current was limited by a number of factors. First, while the model pathways in the current study specified a forward causal direction, it is likely that some of these relationships were in fact bidirectional. Indeed, indicators of appetitive goal pursuit are interrelated and can build off one another. For example, activation of goal pursuit draws one's expectations and attention toward appetitive stimuli (Kim, 2013) which, in turn, can lead to positive affect. The reverse can also take place, wherein positive affect becomes a source of informational feedback that promotes further goal pursuit (Orehek et al., 2011).

Additionally, although the sequence of variables presented in each of the mediation models was consistent with the order in which they were measured, this does not guarantee that changes in certain variables took place at the exact time of measurement. For instance, we measured approach motivation and positive affect at the end of the study (i.e., following the social media activity) but did not track changes across these, or the other outcome measures, across multiple time points. Thus, we cannot be certain precisely when changes in these measures took place: it is possible that positive affect became elevated as soon as the social media activity began, and our measure of positive affect represented this early elevation and not one that specifically followed an activated desire to affiliate. A similar concern is that the state curiosity measure was collected immediately following the social pain measure, which did not afford a meaningful separation between these time points, thereby limiting our ability to claim that changes in social pain truly occurred before curiosity, as outlined in exploratory model 1 .

As well, although our study relied primarily on well-validated measures, some of our measures were unvalidated. For example, by only using a select few items from the State-Trait Curiosity Inventory (Naylor, 1981) to limit participants' response fatigue, we sacrificed our ability to rely on the validity data presented in Naylor (1981) that-with the full scale-would support our claim that this was indeed a valid measure of state curiosity. Moreover, we used unvalidated measures of reward and threat anticipation; however, their psychometric properties and discriminant validity were strong, as outlined in the Supplementary Materials.

The validity of our social pain measure is also an issue worth highlighting. Researchers have conceptualized social pain as a diffuse, negative emotion state involving a combination of anger, fear, sadness, and general upset that arises from an appraisal of having been rejected or hurt by others (Leary et al., 1998). This approach informed how we conceptualized and measured social pain in the present study. Following prior research (Auyeung \& Alden, 2016), we measured social pain with the PANAS negative affect subscale in addition to two items assessing rejection and exclusion. Although there is no clear consensus based on psychometric data of the gold standard measurement of social pain, we opted for the approach used in the current study for three reasons: First, the PANAS-N includes items that capture diffuse, negative emotion states that have been suggested to be characteristic of social pain (as per Leary et al., 1998), such as "I feel upset" and "I feel distressed"). Second, the additional two items that measured perceived feelings of having been rejected and excluded directly connect the source of emotional distress to the relational event (Cyberball exclusion). Third, we replicated the measurement of social pain utilized by Hudd and Moscovitch (2020), which enables us to follow-up directly on hypotheses preliminarily outlined in that earlier paper.

There were also limitations related to the external validity of this study. First, the nature and degree of social pain generated by the online Cyberball task may not have resembled the pain that individuals tend to experience when their feelings are hurt within their close relationships. Although Cyberball has been shown across multiple previous studies to be a reliable method for eliciting the pain of exclusion and amplifying perceptions of relational devaluation (e.g., Hartgerink et al., 2015; Hudd \& Moscovitch, 2020; Zadro et al., 2006), researchers have suggested that relational devaluation is often even more painful in close relationship contexts or in contexts where the perceived reason for being rejected could hold personally relevant implications (Hudd \& Moscovitch, 2021; Leary et al., 1998; Romero-Canyas et al., 2010). Thus, the social pain literature could benefit from future studies that directly capture an individual's in-situ responses to painful interpersonal events and how they might vary as a function relational closeness (e.g., Laws et al., 2017).

The external validity of our study was also limited because participating in the social media game was not optional; therefore, we cannot know for certain whether our findings would generalize to real life social contexts in which people must exert greater personal effort to connect with others. At the same time, we face many social contexts incidentally in our daily lives, without having to make concerted efforts to find and approach others. Indeed, many situations offer social opportunities in which individuals can choose to what extent they will make efforts to affiliate (e.g., checking in for an appointment and choosing to make smalltalk with a front-desk employee versus immediately taking a seat in the waiting room). To some extent, this experience is comparable to what participants experienced during the current study. Within the social media activity, participants did not have to make a concerted effort to approach the activity because it was non-optional, but they could choose what they wished to write in their social media profile. Future studies of SA may wish to examine how avoidance versus approach goals operate within the range of possibilities for social engagement in any given situation. It is possible, for 
instance, that reward responsivity and resulting positive affective experiences may be a stronger predictor of social approach initiation or of the desire to take advantage of new social opportunities that arise (Gable, 2006), whereas threat responsivity may be a stronger predictor of 'holding back' and using subtle avoidance strategies within already-occurring social exchanges (Gray et al., 2019).

It is also essential to note that data from the current study were collected during the global COVID-19 pandemic. During this time, Canadian and American participants would have either recently experienced or were currently experiencing a period of social distancing, which may have affected their desire or motivation to affiliate socially with others.

\section{Future Research and Conclusions}

Despite these limitations, results of the present study help to advance our understanding of the mechanisms involved in facilitating social reconnection following exclusion and the factors that may inhibit social repair for individuals with higher levels of trait SA, suggesting fruitful avenues for future research. While the current study focused on socialterm outcomes for high SA individuals within the context of a 30-min experiment, findings suggest the potential importance of future research designed to observe longerterm effects over more prolonged time periods and across various types of socially painful situations. In the long-term, a diminished ability to perceive social rewards and derive positive affect from social situations may produce culminated, downstream losses. These losses could occur at multiple stages, beginning with the process of memory encoding. Positive affect has been associated with our ability to more effectively integrate old and new information, which may prompt someone who was recently excluded to contextualize the unpleasant event instead of isolating its meaning as a negative focal point (Zbozinek \& Craske, 2017). Beyond encoding, memory retrieval could be impacted as well, as a rewarding interaction following a socially painful event could become an emotionally salient source of retrieval competition against socially painful memories (Brewin, 2006). In other words, anticipating or perceiving pleasurable social rewards soon after a socially painful event may serve to recontextualize or compete with the meaning of the painful event. Because those with high SA display signs of diminished social reward responsivity and positive affect, their socially painful encounters may sustain a more prominent negative impact over time.

In support of this interpretation, some studies have shown that individuals with high SA may carry with them the sustained negative impact of their past socially painful experiences. For example, those with high SA tend to recover their needs more slowly following socially painful events (Zadro et al., 2006) and they tend to draw more selfreferential information from socially painful memories and re-experience them in greater detail and with more accompanied distress (Morgan, 2010; Moscovitch et al., 2011, 2018). Some authors have theorized that evidence of high SA individuals' lower baseline reward perception and responsivity may begin with early and repetitive socially painful events (Richey et al., 2019); indeed, animal-based social defeat models indicate that early or persistent social exclusions or "defeats" cause decreases in reward-based neural activation over time (Carlton et al., 2020). Notably, within the SAD literature there is evidence that suggests that memories of early social "defeats" (e.g., bullying, rejection, etc.) are common among those with high SA and can negatively impact current views of self (Hackmann et al., 2000; Merrifield et al., 2013; Park et al., 2017; Pontillo et al., 2019).

It is noteworthy that being assigned to the inclusion condition and experiencing higher social pain both predicted higher approach motivation for participants in the present study. At first glance, these findings may seem contradictory since included participants also experienced less social pain overall at the group level. However, we believe these results may point to the mediating roles of negative and positive affect in promoting social approach following exclusion or inclusion, respectively. These findings suggest that both the pain of exclusion and the thrill of inclusion may be involved in promoting social approach motivation in social situations, depending on the nature of the context. Future studies should test the hypothesis that individuals who are less reactive emotionally to either exclusion or inclusion (i.e., those who report lower NA/social pain in response to exclusion or lower PA in response to inclusion) may be less likely to desire further social engagement.

Finally, while some researchers have proposed that social threat blocks socially anxious individuals' ability to recognize rewards and shift into an approach-oriented mindset (Becker et al., 2017; Maner et al., 2012), others have suggested that high SA is associated with dampened social reward responsivity, irrespective of levels of perceived threat. In accordance with the latter perspective, we found that high SA participants experienced dampened social reward responsivity and positive affect, irrespective of their levels of social pain. Therefore, findings support the importance of clinical interventions for SAD that target social anhedonia directly rather than presuming that interventions that succeed at alleviating threat hyperresponsivity will automatically enable socially anxious individuals to have more rewarding social experiences. To this end, clinicians may guide patients to challenge their assumptions and beliefs pertaining to low reward drive. Current conceptualizations of SAD emphasize the centrality of negative core beliefs and schemas, such as those that characterize 
the self as being fundamentally deficient (e.g., unintelligent, incompetent, unattractive) and others as being judgmental and likely to respond harshly if these flaws are exposed for scrutiny (see Moscovitch, 2009). Based on the current findings, it is possible that individuals with SAD also hold assumptions and beliefs that more directly pertain to low reward drive, such as "this social event will be a chore, I will not enjoy talking to anyone." Although clinicians may typically be drawn to guiding their socially anxious patients to challenge threat-based thought content because anxiety reduction is often the implied target therapy outcome, recent studies have shown that targeting and increasing positive affect experiences directly can promote responsiveness to SAD treatments, improve feelings of social connectedness, and reduce anxiety, stress, low mood and suicidal ideation more effectively than treatments which seek to reduce negative affect alone (Taylor et al., 2017, 2020).

Supplementary Information The online version contains supplementary material available at https://doi.org/10.1007/s10608-021-10263-z.

\section{Declarations}

Conflict of Interest Taylor Hudd and David A. Moscovitch declare that they have no conflict of interest.

Ethical Approval The following research was approved by the Office of Research Ethics at the University of Waterloo, \#42502.

Informed Consent The following research was conducted in compliance with ethical standards, including informed consent.

Animal rights statements No animal studies were carried out by the authors for this article.

\section{References}

Anderson, C., \& Berdahl, J. L. (2002). The experience of power: Examining the effects of power on approach and inhibition tendencies. Journal of Personality and Social Psychology, 83(6), 1362-1377. https://doi.org/10.1037//0022-3514.83.6.1362

Auyeung, K. W., \& Alden, L. E. (2016). Social anxiety and empathy for social pain. Cognitive Therapy and Research, 40(1), 38-45. https://doi.org/10.1007/s10608-015-9718-0

Bantin, T., Stevens, S., Gerlach, A. L., \& Hermann, C. (2016). What does the facial dot-probe task tell us about attentional processes in social anxiety? A systematic review. Journal of Behavior Therapy and Experimental Psychiatry. https://doi.org/10.1016/j.jbtep. 2015.04.009

Becker, M. P. I., Simon, D., Miltner, W. H. R., \& Straube, T. (2017). Altered activation of the ventral striatum under performancerelated observation in social anxiety disorder. Psychological Medicine, 47(14), 2502-2512. https://doi.org/10.1017/S0033 291717001076

Bielak, T., \& Moscovitch, D. (2013). How do I measure up? The impact of observable signs of anxiety and confidence on interpersonal evaluations in social anxiety. Cognitive Therapy and Research, 37(2), 266-276. https://doi.org/10.1007/s10608-012-9473-4
Blay, Y., Keshet, H., Friedman, L., \& Gilboa-Schechtman, E. (2021). Interpersonal motivations in social anxiety: Weakened approach and intensified avoidance motivations for affiliation and socialrank. Personality and Individual Differences, 170, 110449. https:// doi.org/10.1016/j.paid.2020.110449

Brewin, C. R. (2006). Understanding cognitive behaviour therapy: A retrieval competition account. Behaviour Research and Therapy, 44(6), 765-784. https://doi.org/10.1016/j.brat.2006.02.005

Carlton, C. N., Sullivan-Toole, H., Ghane, M., \& Richey, J. A. (2020). Reward circuitry and motivational deficits in social anxiety disorder: What can be learned from mouse models? Frontiers in Neuroscience. https://doi.org/10.3389/fnins.2020.00154

Chester, D. S., DeWall, C. N., \& Pond, R. S. (2016). The push of social pain: Does rejection's sting motivate subsequent social reconnection? Cognitive, Affective, \& Behavioral Neuroscience, 16(3), 541-550. https://doi.org/10.3758/s13415-016-0412-9

Clark, D. M., \& Wells, A. (1995). A cognitive model of social phobia. In R. G. Heimberg, M. R. Liebowitz, D. A. Hope \& F. R. Schneier (Eds.), Social phobia: Diagnosis, assessment, and treatment (1995-98887-004; pp. 69-93). Guilford Press.

Connor, K. M., Davidson, J. R. T., Churchill, L. E., Sherwood, A., Weisler, R. H., \& Foa, E. (2000). Psychometric properties of the Social Phobia Inventory (SPIN): New self-rating scale. The British Journal of Psychiatry, 176(4), 379-386. https://doi.org/10. 1192/bjp.176.4.379

Cremers, H. R., Veer, I. M., Spinhoven, P., Rombouts, S. A. R. B., \& Roelofs, K. (2015). Neural sensitivity to social reward and punishment anticipation in social anxiety disorder. Frontiers in Behavioral Neuroscience. https://doi.org/10.3389/fnbeh.2014.00439

Derfler-Rozin, R., Pillutla, M., \& Thau, S. (2010). Social reconnection revisited: The effects of social exclusion risk on reciprocity, trust, and general risk-taking. Organizational Behavior and Human Decision Processes, 112(2), 140-150. https://doi.org/10. 1016/j.obhdp.2010.02.005

DeWall, C. N., Maner, J. K., \& Rouby, D. A. (2009). Social exclusion and early-stage interpersonal perception: Selective attention to signs of acceptance. Journal of Personality and Social Psychology, 96(4), 729-741. https://doi.org/10.1037/a0014634

Eisenberger, N. I. (2012). The neural bases of social pain: Evidence for shared representations with physical pain. Psychosomatic Medicine, 74(2), 126-135. https://doi.org/10.1097/PSY.0b013 e3182464dd1

Eisenberger, N. I. (2015). Social pain and the brain: Controversies, questions, and where to go from here. Annual Review of Psychology, 66(1), 601-629. https://doi.org/10.1146/annur ev-psych-010213-115146

Eisenberger, N. I., Lieberman, M. D., \& Williams, K. D. (2003). Does rejection hurt? An FMRI study of social exclusion. Science (New York, N.Y.), 302(5643), 290-292. https://doi.org/10.1126/science. 1089134

Fung, K., \& Alden, L. E. (2016). Once hurt, twice shy: Social pain contributes to social anxiety. Emotion. https://doi.org/10.1037/ emo0000223

Gable, S. L. (2006). Approach and avoidance social motives and goals. Journal of Personality, 74(1), 175-222. https://doi.org/10.1111/j. 1467-6494.2005.00373.x

Glazier, B. L., \& Alden, L. E. (2019). Social anxiety disorder and memory for positive feedback. Journal of Abnormal Psychology, 128(3), 228-233. https://doi.org/10.1037/abn0000407

Gray, E., Beierl, E. T., \& Clark, D. M. (2019). Sub-types of safety behaviours and their effects on social anxiety disorder. PLoS One, 14(10), e0223165. https://doi.org/10.1371/journal.pone.0223165

Gruber, M. J., \& Ranganath, C. (2019). How curiosity enhances hippocampus-dependent memory: The prediction, appraisal, curiosity, and exploration (PACE) framework. Trends in Cognitive 
Sciences, 23(12), 1014-1025. https://doi.org/10.1016/j.tics.2019. 10.003

Hackmann, A., Clark, D. M., \& McManus, F. (2000). Recurrent images and early memories in social phobia. Behaviour Research and Therapy, 38(6), 601-610. https://doi.org/10.1016/S0005-7967(99) 00161-8

Harb, G. C., Heimberg, R. G., Fresco, D. M., Schneier, F. R., \& Liebowitz, M. R. (2002). The psychometric properties of the Interpersonal Sensitivity Measure in social anxiety disorder. Behaviour Research and Therapy, 40(8), 961-979. https://doi. org/10.1016/S0005-7967(01)00125-5

Hartgerink, C. H. J., van Beest, I., Wicherts, J. M., Williams, K. D., \& Van Yperen, N. W. (2015). The ordinal effects of ostracism: A meta-analysis of 120 cyberball studies. PLOS ONE, 10(5), e0127002. https://doi.org/10.1371/journal.pone.0127002.

Hayes, A. F. (2017). Introduction to mediation, moderation, and conditional process analysis: A regression-based approach. The Guilford Press.

Hudd, T., \& Moscovitch, D. A. (2020). Coping with social wounds: How social pain and social anxiety influence access to social rewards. Journal of Behavior Therapy and Experimental Psychiatry, 68, 101572. https://doi.org/10.1016/j.jbtep.2020.101572

Hudd, T., \& Moscovitch, D. A. (2021). Social pain and the role of imagined social consequences: Why personal adverse experiences elicit social pain with or without explicit relational devaluation. Journal of Experimental Social Psychology. https://doi.org/10. 1016/j.jesp.2021.104121

Kashdan, T. B. (2007). Social anxiety spectrum and diminished positive experiences: Theoretical synthesis and meta-analysis. Clinical Psychology Review, 27(3), 348-365. https://doi.org/10.1016/j.cpr. 2006.12.003

Kim, S. (2013). Neuroscientific model of motivational process. Frontiers in Psychology. https://doi.org/10.3389/fpsyg.2013.00098

Koban, L., Schneider, R., Ashar, Y. K., Andrews-Hanna, J. R., Landy, L., Moscovitch, D. A., Wager, T. D., \& Arch, J. J. (2017). Social anxiety is characterized by biased learning about performance and the self. Emotion (Washington, D.C.), 17(8), 1144-1155. https:// doi.org/10.1037/emo0000296

Kunstman, J. W., \& Maner, J. K. (2011). Sexual overperception: Power, mating motives, and biases in social judgment. Journal of Personality and Social Psychology, 100(2), 282-294. https://doi.org/10. 1037/a0021135

Laws, H. B., Ellerbeck, N. E., Rodrigues, A. S., Simmons, J. A., \& Ansell, E. B. (2017). Social rejection and alcohol use in daily life. Alcoholism, Clinical and Experimental Research, 41(4), 820-827. https://doi.org/10.1111/acer.13347

Leary, M. R., \& Springer, C. A. (2000). Hurt feelings: The neglected emotion (p. 151). https://doi.org/10.1037/10365-006

Leary, M. R., Springer, C., Negel, L., Ansell, E., \& Evans, K. (1998). The causes, phenomenology, and consequences of hurt feelings. Journal of Personality and Social Psychology, 74(5), 1225. https://doi.org/10.1037/0022-3514.74.5.1225

Lovibond, P. F., \& Lovibond, S. H. (1995). The structure of negative emotional states: Comparison of the Depression Anxiety Stress Scales (DASS) with the Beck Depression and Anxiety Inventories. Behaviour Research and Therapy, 33(3), 335-343. https://doi.org/ 10.1016/0005-7967(94)00075-U.

MacDonald, G., \& Leary, M. R. (2005). Why does social exclusion hurt? The relationship between social and physical pain. Psychological Bulletin, 131(2), 202-223. https://doi.org/10.1037/00332909.131.2.202

Mallott, M. A., Maner, J. K., DeWall, N., \& Schmidt, N. B. (2009). Compensatory deficits following rejection: The role of social anxiety in disrupting affiliative behavior. Depression and Anxiety, 26(5), 438-446. https://doi.org/10.1002/da.20555
Maner, J. K., DeWall, C. N., Baumeister, R. F., \& Schaller, M. (2007). Does social exclusion motivate interpersonal reconnection? Resolving the "porcupine problem." Journal of Personality and Social Psychology, 92(1), 42-55. https://doi.org/10.1037/00223514.92.1.42

Maner, J. K., Gailliot, M. T., Menzel, A. J., \& Kunstman, J. W. (2012). Dispositional anxiety blocks the psychological effects of power. Personality and Social Psychology Bulletin, 38(11), 1383-1395.

Manning, J., Reynolds, G., Saygin, Z. M., Hofmann, S. G., Pollack, M., Gabrieli, J. D. E., \& Whitfield-Gabrieli, S. (2015). Altered resting-state functional connectivity of the frontal-striatal reward system in social anxiety disorder. PLoS One. http://psycnet.apa. org/index.cfm?fa =search.displayRecord\&id=7F8CB1D7-B26680ED-6495-67FC52E0CDAB \& resultID $=2 \&$ page $=1 \& \mathrm{dbTab}=$ all\&search=true

Mead, N. L., Baumeister, R. F., Stillman, T. F., Rawn, C. D., \& Vohs, K. D. (2011). Social exclusion causes people to spend and consume strategically in the service of affiliation. Journal of Consumer Research, 37(5), 902-919. https://doi.org/10.1086/656667

Merrifield, C., Balk, D., \& Moscovitch, D. A. (2013). Self-portrayal concerns mediate the relationship between recalled teasing and social anxiety symptoms in adults with anxiety disorders. Journal of Anxiety Disorders, 27(5), 456-460. https://doi.org/10.1016/j. janxdis.2013.05.007.

Min, D., \& Kim, J.-H. (2013). Is power powerful? Power, confidence, and goal pursuit. International Journal of Research in Marketing, 30(3), 265-275. https://doi.org/10.1016/j.ijresmar.2012.12.001

Moitra, E., Herbert, J. D., \& Forman, E. M. (2008). Behavioral avoidance mediates the relationship between anxiety and depressive symptoms among social anxiety disorder patients. Journal of Anxiety Disorders, 22(7), 1205-1213. https://doi.org/10.1016/j. janxdis.2008.01.002

Morgan, J. (2010). Autobiographical memory biases in social anxiety. Clinical Psychology Review, 30(3), 288-297. https://doi.org/10. 1016/j.cpr.2009.12.003

Moscovitch, D. A. (2009). What is the core fear in social phobia? A new model to facilitate individualized case conceptualization and treatment. Cognitive and Behavioral Practice, 16(2), 123-134. https://doi.org/10.1016/j.cbpra.2008.04.002

Moscovitch, D. A., Gavric, D. L., Merrifield, C., Bielak, T., \& Moscovitch, M. (2011). Retrieval properties of negative vs. positive mental images and autobiographical memories in social anxiety: Outcomes with a new measure. Behaviour Research and Therapy, 49(8), 505-517. https://doi.org/10.1016/j.brat.2011.05.009

Moscovitch, D. A., Rodebaugh, T. L., \& Hesch, B. D. (2012). How awkward! Social anxiety and the perceived consequences of social blunders. Behaviour Research and Therapy, 50(2), 142-149. https://doi.org/10.1016/j.brat.2011.11.002

Moscovitch, D. A., Waechter, S., Bielak, T., Rowa, K., \& McCabe, R. E. (2015). Out of the shadows and into the spotlight: Social blunders fuel fear of self-exposure in social anxiety disorder. Journal of Anxiety Disorders, 34, 24-32. https://doi.org/10.1016/j.janxd is.2015.06.004

Moscovitch, D. A., Vidovic, V., Lenton-Brym, A. P., Dupasquier, J. R., Barber, K. C., Hudd, T., Zabara, N., \& Romano, M. (2018). Autobiographical memory retrieval and appraisal in social anxiety disorder. Behaviour Research and Therapy, 107, 106-116. https:// doi.org/10.1016/j.brat.2018.06.008

Narayanan, J., Tai, K., \& Kinias, Z. (2013). Power motivates interpersonal connection following social exclusion. Organizational Behavior and Human Decision Processes, 122(2), 257-265. https://doi.org/10.1016/j.obhdp.2013.08.006

Naylor, F. D. (1981). A state-trait curiosity inventory. Australian Psychologist, 16(2), 172-183. https://doi.org/10.1080/0005006810 8255893 
Nordgren, L. F., Banas, K., \& MacDonald, G. (2011). Empathy gaps for social pain: Why people underestimate the pain of social suffering. Journal of Personality and Social Psychology, 100(1), 120-128. https://doi.org/10.1037/a0020938

Orehek, E., Bessarabova, E., Chen, X., \& Kruglanski, A. W. (2011). Positive affect as informational feedback in goal pursuit. Motivation and Emotion, 35(1), 44-51. https://doi.org/10.1007/ s11031-010-9197-2

Page, A. C., Hooke, G. R., \& Morrison, D. L. (2007). Psychometric properties of the Depression Anxiety Stress Scales (DASS) in depressed clinical samples. British Journal of Clinical Psychology, 46(3), 283-297. https://doi.org/10.1348/014466506X158996

Park, A., Jensen-Campbell, L. A., \& Miller, H. L. (2017). The effects of peer relational victimization on social cognition: Rejection attribution bias or a more generalized sensitivity to social pain? Journal of Social and Personal Relationships, 34(7), 984-1006. https://doi.org/10.1177/0265407516664418

Pontillo, M., Tata, M. C., Averna, R., Demaria, F., Gargiullo, P., Guerrera, S., Pucciarini, M. L., Santonastaso, O., \& Vicari, S. (2019). Peer victimization and onset of social anxiety disorder in children and adolescents. Brain Sciences, 9(6), 132. https://doi.org/ 10.3390/brainsci9060132

Richey, J. A., Rittenberg, A., Hughes, L., Damiano, C. R., Sabatino, A., Miller, S., Hanna, E., Bodfish, J. W., \& Dichter, G. S. (2014). Common and distinct neural features of social and non-social reward processing in autism and social anxiety disorder. Social Cognitive and Affective Neuroscience, 9(3), 367-377. https://doi. org/10.1093/scan/nss146

Richey, J. A., Brewer, J. A., Sullivan-Toole, H., Strege, M. V., KimSpoon, J., White, S. W., \& Ollendick, T. H. (2019). Sensitivity shift theory: A developmental model of positive affect and motivational deficits in social anxiety disorder. Clinical Psychology Review, 72, 101756. https://doi.org/10.1016/j.cpr.2019.101756

Romano, M., Tran, E., \& Moscovitch, D. A. (2020). Social anxiety is associated with impaired memory for imagined social events with positive outcomes. Cognition and Emotion, 34(4), 700-712. https://doi.org/10.1080/02699931.2019.1675596

Romero-Canyas, R., Downey, G., Reddy, K. S., Rodriguez, S., Cavanaugh, T. J., \& Pelayo, R. (2010). Paying to belong: When does rejection trigger ingratiation? Journal of Personality and Social Psychology, 99(5), 802-823. https://doi.org/10.1037/a0020 013

Schoemann, A. M., Boulton, A. J., \& Short, S. D. (2017). Determining power and sample size for simple and complex mediation models. Social Psychological and Personality Science, 8(4), 379-386. https://doi.org/10.1177/1948550617715068

Simonsohn, U. (2014). [17] No-way interactions. The Winnower. https://doi.org/10.15200/winn.142559.90552.

Sommer, K. L., \& Bernieri, F. (2015). Minimizing the pain and probability of rejection: Evidence for relational distancing and proximity seeking within face-to-face interactions. Social Psychological and Personality Science, 6(2), 131-139. https://doi.org/10.1177/ 1948550614549384

Steinman, S. A., Gorlin, E. I., \& Teachman, B. A. (2014). Cognitive biases among individuals with social anxiety. In The Wiley Blackwell handbook of social anxiety disorder (pp. 321-343). Wiley. https://doi.org/10.1002/9781118653920.ch15
Taylor, C. T., Knapp, S. E., Bomyea, J. A., Ramsawh, H. J., Paulus, M. P., \& Stein, M. B. (2017). What good are positive emotions for treatment? Trait positive emotionality predicts response to Cognitive Behavioral Therapy for anxiety. Behaviour Research and Therapy. https://doi.org/10.1016/j.brat.2017.03.006.

Taylor, C. T., Pearlstein, S. L., Kakaria, S., Lyubomirsky, S., \& Stein, M. B. (2020). Enhancing social connectedness in anxiety and depression through amplification of positivity: Preliminary treatment outcomes and process of change. Cognitive Therapy and Research, 44(4), 788-800. https://doi.org/10.1007/ s10608-020-10102-7.

Vassilopoulos, S. P., \& Banerjee, R. (2010). Social interaction anxiety and the discounting of positive interpersonal events. Behavioural and Cognitive Psychotherapy, 38(5), 597-609. https://doi.org/10. 1017/S1352465810000433

Watson, D., Clark, L. A., \& Tellegen, A. (1988). Development and validation of brief measures of positive and negative affect: The PANAS scales. Journal of Personality and Social Psychology, 54(6), 1063-1070. https://doi.org/10.1037//0022-3514.54.6.1063

Weeks, J. W., \& Howell, A. N. (2012). The bivalent fear of evaluation model of social anxiety: Further integrating findings on fears of positive and negative evaluation. Cognitive Behaviour Therapy, 41(2), 83-95. https://doi.org/10.1080/16506073.2012.661452

Weisman, O., Aderka, I. M., Marom, S., Hermesh, H., \& GilboaSchechtman, E. (2011). Social rank and affiliation in social anxiety disorder. Behaviour Research and Therapy, 49(6-7), 399-405. https://doi.org/10.1016/j.brat.2011.03.010

Wesselmann, E. D., Wirth, J. H., \& Bernstein, M. J. (2017). Expectations of social inclusion and exclusion. Frontiers in Psychology. https://doi.org/10.3389/fpsyg.2017.00112

Williams, K. D., Cheung, C. K. T., \& Choi, W. (2000). Cyberostracism: Effects of being ignored over the Internet. Journal of Personality and Social Psychology, 79(5), 748-762. https://doi.org/10.1037/ 0022-3514.79.5.748

Wolf, W., Levordashka, A., Ruff, J. R., Kraaijeveld, S., Lueckmann, J.-M., \& Williams, K. P. (2015). Ostracism online: A social media ostracism paradigm. Behavior Research Methods, 47(2), 361-373. https://doi.org/10.3758/s13428-014-0475-x

Zadro, L., Williams, K. D., \& Richardson, R. (2004). How low can you go? Ostracism by a computer is sufficient to lower self-reported levels of belonging, control, self-esteem, and meaningful existence. Journal of Experimental Social Psychology, 40(4), 560-567. https://doi.org/10.1016/j.jesp.2003.11.006

Zadro, L., Boland, C., \& Richardson, R. (2006). How long does it last? The persistence of the effects of ostracism in the socially anxious. Journal of Experimental Social Psychology, 42(5), 692-697. https://doi.org/10.1016/j.jesp.2005.10.007

Zbozinek, T. D., \& Craske, M. G. (2017). The role of positive affect in enhancing extinction learning and exposure therapy for anxiety disorders. Journal of Experimental Psychopathology, 8(1), 13-39. https://doi.org/10.5127/jep.052615

Publisher's Note Springer Nature remains neutral with regard to jurisdictional claims in published maps and institutional affiliations. 